\title{
Analysis of Wellbore Drilling Hydraulics Applying a Transient Godunov Scheme Considering Variations of Injected Flow Rates
}

\author{
Rubén Nicolás-López ${ }^{1}$, Angel Sánchez-Barra², Oscar Valdiviezo-Mijangos ${ }^{1}$ \\ ${ }^{1}$ Mexican Petroleum Institute, Mexico, MEX \\ ${ }^{2}$ Department of Petroleum Engineering, Faculty of Engineering, Autonomous National University of Mexico, Mexico, MEX
}

Email address:

ovaldivi@imp.mx (O. Valdiviezo-Mijangos)

\section{To cite this article:}

Rubén Nicolás-López, Angel Sánchez-Barra, Oscar Valdiviezo-Mijangos. Analysis of Wellbore Drilling Hydraulics Applying a Transient Godunov Scheme Considering Variations of Injected Flow Rates. International Journal of Oil, Gas and Coal Engineering.

Vol. 5, No. 5, 2017, pp. 116-123. doi: 10.11648/j.ogce.20170505.16

Received: May 30, 2017; Accepted: June 6, 2017; Published: October 24, 2017

\begin{abstract}
A new application of the Godunov scheme to describe dynamic oil-well behavior is presented. The numerical model is able to capture discontinuities associated with surface flow-rate variations. The finite volume method and Riemann problems are utilized for building the unsteady discrete solution. Initial and boundary conditions are related to cases of static, steady and transient well condition. Well data used in simulation are taken from true operational conditions and well mechanical configuration. The results of Godunov's modeling describe the behavior of transient pressure and transient flow rate inside drill pipe and annulus. These profiles are commonly caused by turning on, adjusting mud flow rate and turning off the rig pumps. The evaluated rig indicators are: back pressure, pumping pressure, bottomhole pressure and injected flow rate. Calculated transient profiles are physically consistent and in good agreement with published well data. Therefore, engineering contribution is the application of first-order Godunov method to evaluate the transient hydraulics whereas variations of mud flow rate; also, the analysis and interpretation of the dynamic pressure behavior travelling inside the well. The Godunov scheme has robust engineering applications for modeling the transient drilling hydraulics, e.g., managed pressure drilling, hydraulics of pipe connections, and foam cementing, as well.
\end{abstract}

Keywords: Drilling Hydraulics, Godunov Scheme, Managed Pressure Drilling, Bottom-Hole Pressure

\section{Introduction}

Drilling hydraulics includes the cases of static, steady and transient wellbore conditions. For instance: any no-flowing wells are also named static well; constant circulating flow rate denotes steady well; and transitions from pumps-on and pumps-off, while mud flow rate is being adjusted or during pipe connection corresponds to a transient well performance. To describe these cases, many steady models have been developed [1] however, the classical drilling hydraulic models utilized to manage the annular pressure profile cannot capture transient flow discontinuities; i.e. mechanistic hydraulic model. Some emerging transient models are unfortunately characterized by high-priced computing budget and complexity [2], [3] and [4]. For instance, the paper [5] is a very interesting paper because it clarifies that transient emerging models have potential applications to fully simulate underbalanced operations. Also, it deeply discusses how efficiency and accuracy are improved by the combination of numerical schemes. Unfortunately, some hydraulic parameters as volumetric fractions and sound velocities of flowing phases cannot directly measured at well location; the intensive use of these kind of models needs the complete set of input data; in the future, we believe that modern and intelligent DAQ systems will support this drawback. Therefore, this research is divided in three main stages: (1) Transient hydraulics model, (2) Numerical solution, and (3) Validation with a recommended practice of the American Petroleum Institute [6]. The math model, closure relationships and initial-boundary conditions are established considering true drilling conditions and the main hydraulics mechanisms. The robust numerical solution to implement in 
any programming language has been developed applying the Godunov method. The dynamic well bearing is validated through using well data and flow rate variations in accordance with the best field practices.

There are discrete solutions that have been applied for drilling hydraulics modeling, e.g. the most popular are difference finite and volume finite scheme [7], [8], [9]. Here, the discrete solution is based on the Godunov scheme [10], because it deals very well with the tracking of pressure and flow-rate wave front along the well. Also, it has been supported by the evaluation of the Riemann problem for each cell of the computational domain. The Riemann problem can capture flow discontinuities; by doing so, proactive control of transient annular pressure could be carried out on site. This is imperative to respond immediately to dynamic wellbore events because too much pressure fluctuations in the field can cause loss/collapse issue, well kick, gas cut mud, or shallow gas. Therefore, the numerical solution is consistent with the physical fact that drilling fluid always circulates as a "solidliquid" bar before and after the discontinuities generated by the flow rate variation. The analyzed transient hydraulics includes the contribution of potential energy related to the mud weight, and the change of kinetic energy caused by the frictional losses generated because drilling fluid is circulating in the well sections. Moreover, the history of hydraulics simulation clearly represents the dynamic well behavior represented by static, transient and steady well conditions. The resulting pressure and flow-rate profiles are plotted versus true vertical depth and length of simulation to depict how the discontinuities are travelling along the well. Additionally, they are widely validated together with hydraulics data of oil well drilling.

The above mentioned describes the research contribution. This deals with the dynamic behavior of wellbore considering controlled flow-rate variations. In drilling, this well condition is very common; i.e. when the driller is adjusting mud flow rate for better hole cleaning, during pipe connections or utilizing an automatic control of rig pumps; the driller mainly acts based on his field experience and well off-set data of previous interventions. The potential application on managed pressure drilling is discussed; and it is found that as a result of the inertial phenomenon of the pressure wave travelling, the well flows as similarly as to the starting of a well kick through the annulus space. The next article section explains the math model and a Godunov discrete solution, the numerical results of transient hydraulics; finally, the main conclusions are stated.

\section{Mathematical Model of Transient Hydraulics}

The drilling hydraulics is analyzed through a conservative scheme of the governing equations (Eq. 1). The onedimensional transient model is composed by mass and momentum equations as,

$$
\frac{\partial \Phi}{\partial t}+\frac{\partial F}{\partial x}=\mathrm{S}
$$

$$
\Phi=\left[\begin{array}{c}
\mu \\
q_{m}
\end{array}\right], F=\left[\begin{array}{c}
\mu u \\
A p+u q_{m}
\end{array}\right], S=\left[\begin{array}{c}
0 \\
-f_{D}|u| u+\rho g A
\end{array}\right]
$$

where $\Phi$ represents the conservative variables: $\mu=\rho A$, $q_{m}=\mu u=\rho A u, F$ is the flux and $\mathrm{S}$ is the source term, and $x$ is the variable along the well survey. The friction factor is defined by $f_{D}=(f / 2) \cdot \rho P /(2 \rho A)^{2}$; the variables: $p, u$, $\rho, P, g$ and $A$ denote pressure, velocity, density, perimeter, gravity constant, and cross-sectional area, respectively [11]. The generalized scheme of mixture sound celerity $c_{m}$ is used to complete the above system,

$$
c_{m}=\frac{c}{\sqrt{1+\rho \eta_{\mathrm{Ref}} p_{\mathrm{Ref}}^{1 / \theta} / p^{(1+\theta) / \theta}}}
$$

where, $c$ is the velocity of liquid pressure wave, $\eta_{\text {Ref }}$ is the void fraction and $\theta$ which is equal to 1 for isothermal and 1.4 for adiabatic conditions [10]. However, special consideration of mixture viscosity and sound velocity will be required; i.e. at low pressures and gas fraction of 0.1-0.9, the sound velocity is always lower than gas wave velocity and liquid wave velocity. Now, when pure liquid flows with any presence of gas, $c_{m}$ is equal to $c$. Finally, the initial and boundary conditions are established in accordance with well hydraulics,

$\Phi(x, t=0)$ Well geometry in $0 \leq x \leq L$,

$\mathrm{p}(\mathrm{L}, \mathrm{t})$ Constant back pressure,

$$
q_{m}(0, t) \text { Dynamic liquid flow rates }
$$

The initial condition $t=0$ means that entire oil-well conditions are known, usually related to static (no flow) or steady (constant flow) well data. The second represents constant pressure conditions in the choke, where the mud is flowing out the well (right-hand boundary). The last one corresponds to controlled variations of liquid flow rate (lefthand boundary). The solution of this initial-boundary problem is utilized for modeling the dynamic well behavior. The analyzed cases are the conditions of starting or stopping the rig pumps and flow rate adjusting. In order to apply the Godunov scheme, the conservative variables $\Phi$ are evaluated by the Riemann problem at $x=x_{0}$ as follows,

$$
\Phi(x, t)=\left\{\begin{array}{c}
\Phi_{L} \text { for } x \leq x_{0}-c_{m} t \\
\Phi^{*} \text { for } x_{0}-c_{m} t<x \leq x_{0}+c_{m} t \\
\Phi_{R} \text { for } x>x_{0}+c_{m} t
\end{array}\right\}
$$

where $\Phi_{L}, \Phi^{*}$ and $\Phi_{R}$ are the left, intermediate and right states of the Riemann problem, respectively. The combined Equations (1) to (4) establish a very robust transient hydraulics model. All variables of equations have SI units, they can be consistently converted to oil-field units using the SPE metric standards [14]. Next, we will introduce its numerical solution.

\section{Discrete Solution Based on the Godunov Scheme}

Equation 1 is called the differential form of the conservation laws, however, the changes of liquid flow rate generate pressure and flow discontinuities and we must use 
the discrete integral form. For the purpose, the first step is to define finite volumes or cells for the entire physical domain. In the $x-t$ plane, the control volumes are sized by $\left[x_{1-1 / 2}, x_{1+1 / 2}\right] \times\left[t^{n}, t^{n+1}\right]$. They are distributed along the $x$ axis from $i=1$ to $i=N$ and on the time domain from $t=n$ to $t=n+1$. Figure 1 illustrates that left-hand and right-hand boundaries are located at $i=1 / 2$, and $i=N+$ $1 / 2$, respectively. The internal cells are indicated by $i=1$, to $i=N$.

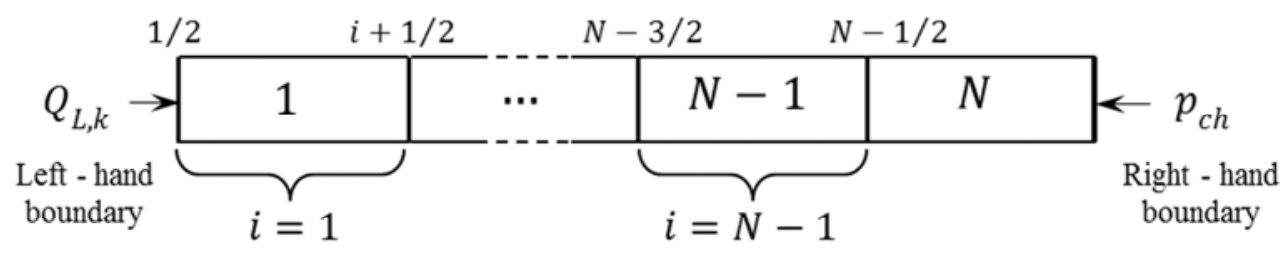

Figure 1. Finite volumes, boundary location

Based on Eq. 1 and applying both processes of line integration and integral averages of $\Phi(x, t)$ and $F$ lead us to the discrete conservative form of the conservation laws [13],

$$
\Phi_{i}^{n+1}=\Phi_{i}^{n}+\frac{\Delta t}{\Delta x_{i}}\left(F_{i-1 / 2}^{n+1 / 2}-F_{i+1 / 2}^{n+1 / 2}\right)+\mathrm{S}\left(\Phi_{i}^{n+1, x}\right) \Delta t
$$

The numerical solution of Eq. 5 is developed applying a basic splitting scheme. Firstly, the solution of pure advection problem $\Phi_{i}^{n+1, x}$ using the initial condition $\Phi_{i}^{n}$ is obtained though

$$
\begin{gathered}
\Phi_{i}^{n+1, x}=\Phi_{i}^{n}+\frac{\Delta t}{\Delta x_{i}}\left(F_{i-1 / 2}^{n+1 / 2}-F_{i+1 / 2}^{n+1 / 2}\right) \\
\Phi_{i}^{n+1, x}=\left(\begin{array}{c}
\mu_{i}^{n+1, x} \\
q_{m, i}^{n+1, x}
\end{array}\right)
\end{gathered}
$$

At this stage, the Godunov scheme supported by the Riemann problem is applied for evaluating the intercell flux $F_{i+1 / 2}^{n+1 / 2}$

$$
F_{i+1 / 2}^{n+1 / 2}=F\left(\begin{array}{c}
\mu_{i}^{n+1, x} \\
q_{m, i}^{n+1, x}
\end{array}\right)=\left[\begin{array}{c}
q_{m, i+1 / 2}^{n+1 / 2} \\
A p_{i+1 / 2}^{n+1 / 2}
\end{array}\right]
$$

The first component of the flux $q_{m, i+1 / 2}^{n+1 / 2}$ is obtained by multiplying $\mu_{i+1 / 2}^{n+1 / 2}$ by $u_{i+1 / 2}^{n+1 / 2}$. The second component $A p_{i+1 / 2}^{n+1 / 2}$ is computed from $\mu_{i+1 / 2}^{n+1 / 2}$ through solving the next equation for $p[14]$,

$$
\mu=\mu_{\text {Ref }}+\frac{A}{c^{2}}\left[p-p_{\text {Ref }}+\left(p_{\text {Ref }}^{-1 / \theta}-p^{-1 / \theta}\right) \alpha \rho \eta_{\text {Ref }} p_{\text {Ref }}^{1 / \theta}\right]
$$

Now, assuming no spatial variations for $\Phi(x, t)$ and taking $\Phi_{i}^{n+1, x}$ as a starting point, which leads us to the final discrete solution,

$$
\Phi_{i}^{n+1}=\Phi_{i}^{n+1, x}+\mathrm{S}\left(\Phi_{i}^{n+1, x}\right) \Delta t
$$

where

$$
\Phi_{i}^{n+1}=\left(\begin{array}{c}
\mu_{i}^{n+1} \\
q_{m, i}^{n+1}
\end{array}\right)=\left(\begin{array}{c}
\mu_{i}^{n+1, x} \\
\frac{q_{m, i}^{n+1, x}+\rho g A \Delta t}{1+\left|q_{m, i}^{n+1, x}\right| f_{D} \Delta t}
\end{array}\right)
$$

Equations (6)-(9) are applied for internal cells, $i=1 \cdots N$. After that, left- and right-hand boundaries $(i=1 / 2$, and $i=N+1 / 2$, respectively) are separately treated for a better understanding. Both of them are closely related to drilling hydraulics. Considering a prescribed pressure, $u_{1 / 2}^{n+1 / 2}$ and $u_{N+1 / 2}^{n+1 / 2}$ are calculated through

$$
\begin{aligned}
& u_{1 / 2}^{n+1 / 2}=u_{1}^{n}+\frac{\left(c_{1}^{n}+c_{b}\right)\left(\mu_{b}-\mu_{1}^{n}\right)}{\mu_{b}+\mu_{1}^{n}} \\
& u_{N+1 / 2}^{n+1 / 2}=u_{N}^{n}+\frac{\left(c_{N}^{n}+c_{b}\right)\left(\mu_{N}^{n}-\mu_{b}\right)}{\mu_{b}+\mu_{N}^{n}}
\end{aligned}
$$

For a prescribed flow discharge, $\mu_{1 / 2}^{n+1 / 2}$ and $\mu_{N+1 / 2}^{n+1 / 2}$ are computed with

$$
\begin{aligned}
& \mu_{1 / 2}^{n+1 / 2}=\left[1+\frac{u_{b}-u_{1}^{n}}{c_{1}^{n}+c\left(\mu_{1 / 2}^{n+1 / 2}\right)}\right] \mu_{1}^{n} \\
& \mu_{N+1 / 2}^{n+1 / 2}=\left[1+\frac{u_{N}^{n}-u_{b}}{c_{N}^{n}+c\left(\mu_{1 / 2}^{n+1 / 2}\right)}\right] \mu_{1}^{n} .
\end{aligned}
$$

These boundary conditions represent drilling hydraulics without sacrificing accuracy in modeling results. Another important numerical condition to assess the evolution of $\Phi_{i}$ from $\Phi_{i}^{n}$ to $\Phi_{i}^{n+1}$ is the computational time step. It must not be larger than the maximum permissible time step $\Delta t_{\text {Max }}$ for the conservative part of the solution and solution procedure of the source term. If an analytical solution is used for the source term, the stability constraint is given by

$$
\Delta t_{\max }=\underset{i=1, \ldots, N}{\operatorname{Min}}\left(\frac{\Delta x_{i}}{|u|+c_{m}}\right)
$$

Here, the math model and its numerical solution have been established. Next, the input data taken from a case of true drilling is explained in detail.

\section{Oil-Well Data for Transient Hydraulics Modeling}

This section describes the integration of oil-well data set 
for dynamic modeling of drilling hydraulics in accordance with engineering concerns and field practice. The study case was taken directly from a standard of the American Petroleum Institute [6], which provides a basic understanding and guidance about drilling fluid rheology and hydraulics, and their application to drilling operations. Well geometry consists of the last string of $95 / 8$ " casing set in the well at $2953 \mathrm{ft}$, an open hole was drilled with a $81 / 2$ " bit from $2953 \mathrm{ft}$ to total depth of $11,975 \mathrm{ft}$; the drill pipe has $11,384 \mathrm{ft}$ and drill collars have $591 \mathrm{ft}$, the bit size is $81 / 2$ " Table 1; with these data the grid of physical domain is constructed. In this case, the flow areas are defined for all well sections based on the well configuration and drillstring, Table 1 . The geometry properties of cemented casing $\mathrm{CS}$, open hole $\mathrm{OH}$, drill pipe DS, drill collars DC and drill bit are used to define the size and location of numerical cells, Figure 1. Moreover, the circulating mud is physically related to well sections.

Table 1. Oil-well geometry [6] and flow sections in field units. Lb: Left boundary, Rb: Right boundary.

\begin{tabular}{l|l|lllll}
\hline 5 & Well Section & Depth [ft] & $\boldsymbol{D}_{\mathbf{1}}$ [in] & $\boldsymbol{D}_{\mathbf{2}}$ [in] & Flow description \\
\cline { 2 - 5 } & 1 & $0(L b)-11384-$ & 3.78 & - & Mud circulating down in drill pipe \\
& 2 & $11384-11975$ & 2.5 & - & Mud circulating down in drill collar \\
& 3 & $11975-11384$ & 8.5 & 6.5 & Mud circulating up in drill collar and open hole \\
\hline & 4 & $11975-2953$ & 8.5 & 4.5 & Mud circulating up in drill pipe and open hole \\
\hline
\end{tabular}

Now, the physical meaning of initial and boundary conditions are stated. They are associated to static, transient and steady oil wells. Left and right boundaries are located at: $i=1 / 2$, and $i=N+1 / 2$, respectively. Mainly, transient flow rates are supported by stepped flow rates $Q_{L, k}$ injected down through the stand pipe. In order to properly represent the process of starting and breaking off the rig pumps, the flow rates $Q_{L, k}$ consist of $0,280,340,280,100$ and 0 gpm.
The upper mud flow rate of 340 gpm was selected for achieving the rule of thumb known as 40 gpm per inch of drill bit size ( $8.5 \mathrm{in})$. This sort of hydraulics analysis grasps the potential application of the Godunov scheme to managed pressure drilling. Therefore the dynamic well behavior is carried out using the operational conditions described in the next Table.

Table 2. Boundary conditions utilized for dynamic modeling of oil-well hydraulics

\begin{tabular}{|c|c|c|c|c|}
\hline & Symbol & Parameter & Value & Time (s) \\
\hline Left boundary, $i=1 / 2$ & $Q_{L, k}$ & Flow rate & $0 \mathrm{gpm}$ & 0 \\
\hline *API-13D (2003) & $Q_{L, k}$ & Flow rate & *280 gpm & 0.1 \\
\hline & $Q_{L, k}$ & Flow rate & $340 \mathrm{gpm}$ & 7.4 \\
\hline *API-13D (2003) & $Q_{L, k}$ & Flow rate & *280 gpm & 14.8 \\
\hline & $Q_{L, k}$ & Flow rate & 100 gpm & 31 \\
\hline & $Q_{L, k}$ & Flow rate & $0 \mathrm{gpm}$ & 41 \\
\hline Right boundary, $i=N+1 / 2$ & $p_{c h}$ & Choke pressure & 0 psi & Overall \\
\hline
\end{tabular}

After that, consistency, convergence and stability of discrete solution are assured with the hydrodynamic and numerical parameters shown in Table 3 . These parameters are mainly related to conditional operations of well hydraulics and oil well configuration. For the purpose, we followed a numerical strategy similar to the case study described in the Appendix.

Table 3. Hydrodynamic and numerical parameters used for transient discrete solution, (Adapted from [6]).

\begin{tabular}{lll}
\hline Symbol & Parameter & Value \\
\hline$c$ & Sound celerity & $3281 \mathrm{ft} / \mathrm{s}$ \\
$f$ & Average friction factor & 0.015 \\
$\theta$ & Coefficient in the perfect gas equation & 1 \\
$\eta_{\text {Ref }}$ & Void fraction at reference pressure & 0 \\
$\rho_{\text {Ref }}$ & Liquid density at reference pressure & $12.43 \mathrm{ppg}$ \\
$\varepsilon_{\mu}$ & Tolerance criterion on $\mu$ & $1 \mathrm{E}^{-6}$ \\
$\varepsilon_{u}$ & Tolerance criterion on $u$ & $1 \mathrm{E}^{-6}$ \\
$I_{M a x}$ & Limit number of iterations & 100 \\
$N$ & Number of cells in the model & 730 \\
$N_{b h}$ & Cell at annular bottomhole depth & 365 \\
$t_{M a x}$ & Time length of the simulation & $50 \mathrm{~s}$ \\
$\Delta x$ & Cell size & $32.8 \mathrm{ft}$ \\
$\Delta t$ & Maximum time step & $0.01 \mathrm{~s}$ \\
\hline
\end{tabular}

\section{Numerical Results}

In the field, an experienced driller knows well that hole cleaning criteria are the basis of flow rate design, and the pore or collapse and fracture pressure govern the mud weight [15]. Flow-rate and mud-weight program are designed previously to site intervention; however, the cases where the drilling hydraulics behaves different to designed operational window as a result of either steeply rising pore pressure, narrow drilling window or inter-bedded loss zones; a kind of "trial and error" scheme is used in the field. To solve it, mudflow rate and mud weight are often stepped up and down during drilling operations until the most favorable value is adjusted. This situation puts the well integrity into risk. Here, these sorts of concerns are addressed by the analysis of dynamic wellbore behavior considering the variations of kinetic and potential energy. Specially to get a better understanding of the wellbore condition generated from transient liquid-flow rates. It is supported by researching how pressure and flow-rate waves travel along the oil-well sections when the mud flow rate is changed. In Figure 2 (left 
side), the well configuration is stated from Table 1; and the well hydraulics while rig pumps start to circulate $280 \mathrm{gpm}$ is shown. In Figure 2, green lines represent pressure profiles when the well is in static conditions and relates initial conditions, Table 2. Also, it quantitatively indicates the relationship between potential energy and mud weight increasing from 8.34 to $11.69 \mathrm{ppg}$. The case study considers working fluid of $12.43 \mathrm{ppg}$. In terms of depth, time and pressure, mud-flow wave of $280 \mathrm{gpm}$ travels in the drillstring as follows: (1640 ft, $0.5 \mathrm{~s}, 2530 \mathrm{psi}),(3280 \mathrm{ft}, 1 \mathrm{~s}, 4546 \mathrm{psi})$, $(4921 \mathrm{ft}, 1.5 \mathrm{~s}, 6604 \mathrm{psi})$. At $3.7 \mathrm{~s}$, the flow-rate wave has already reached the drill bit; however, the mud in annular space remains unaltered because the pressure wave will take longer to perturb the annulus. This could be related to the starting of drilling well stage or during pipe connections. At $0.1 \mathrm{~s}, 280 \mathrm{gpm}$ are pumped by standpipe, the time spent by the pressure wave to travel along inside of the drill pipe and annulus is $7.3 \mathrm{~s}$ considering the wave velocity of $3281 \mathrm{ft} / \mathrm{s}$; it means that the $280 \mathrm{gpm}$ will be returning out to surface after $7.4 \mathrm{~s}$. This fact is related to dynamic conditions, the encoded Godunov scheme consistently captures it. This clearly denotes that the oil well will be at dynamic conditions after $7.4 \mathrm{~s}$. Based on the Godunov scheme, it is established that the circulating drilling fluid behaves as a "solid-liquid bar" before and after pressure discontinuity generated by flow-rate changes. The model capability to represent consistently these complex transient phenomena becomes an important contribution of the article.

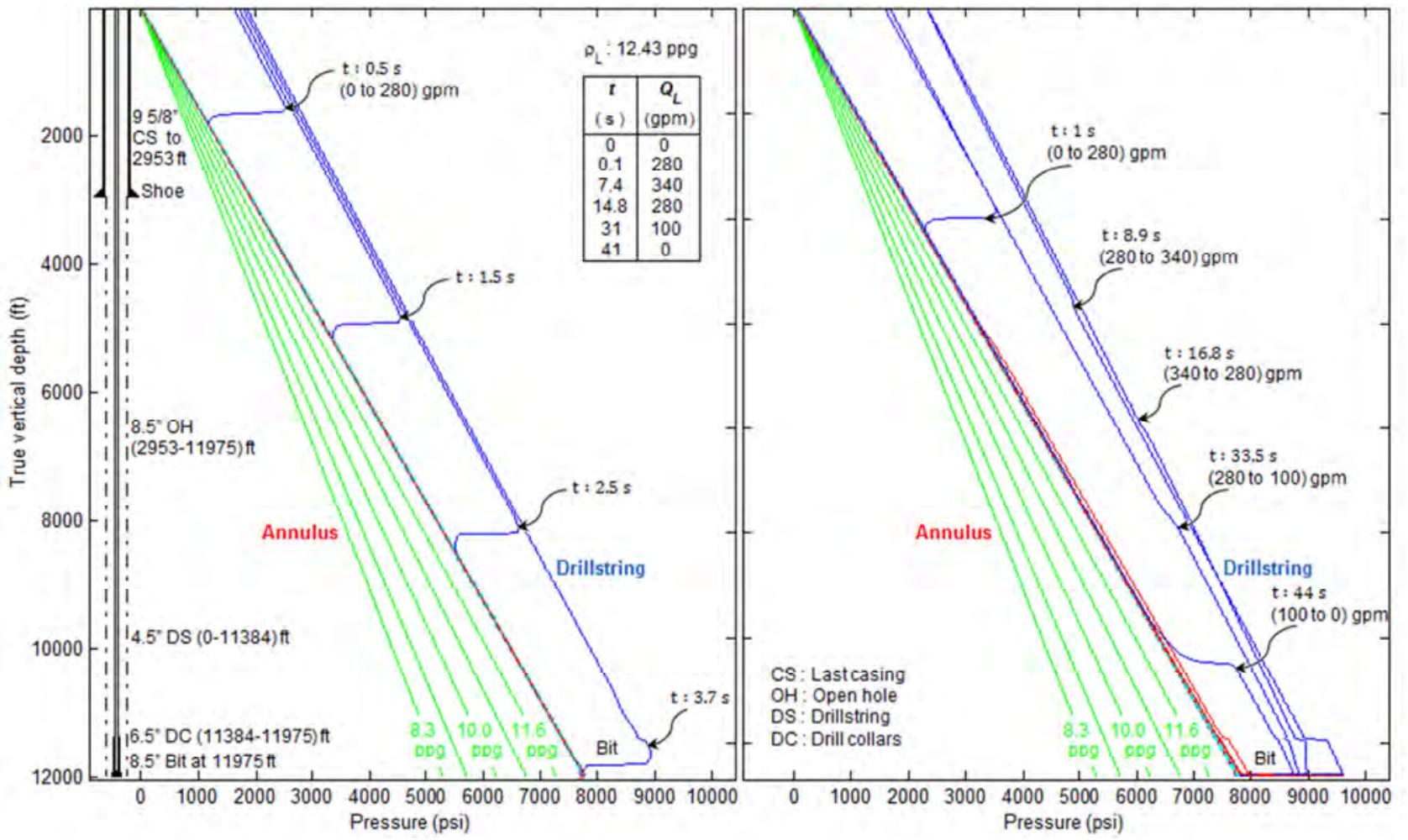

Figure 2. Dynamic well behavior while drilling fluid and pressure wave are travelling through well sections. Green profiles, blue and red lines indicate static well, transient pressure profiles of drillstring and annulus.

Figure 2 (right side) demonstrates that annular transient pressure profiles have small variations considering the boundary conditions in Table 2. It also shows the same effect of mud density variations in green lines. Here, five transient pressure profiles are depicted in order to explain the well dynamic behavior as a result of flow rate changes. They are distributed along well depth for a better graphical account; however, it must be kept in mind that the pressure wave travels in similar way to the left side for whole well sections. Consistently capturing these transient discontinuities represents the main advantage of the Godunov method. Now we describe the pressure fronts. The first pressure front corresponds to $1 \mathrm{~s}$ after turning on the rig pumps and its value is $1252 \mathrm{psi}$; the second represents $1.5 \mathrm{~s}$ after the mud flow rate was changed to $340 \mathrm{gpm}$, now the pressure discontinuity is only $117 \mathrm{psi}$ at $8.9 \mathrm{~s}$ because the oil well was already in dynamic condition. Next, $340 \mathrm{gpm}$ is decreased to $280 \mathrm{gpm}$ and pressure front is $-200 \mathrm{psi}$, slightly different because the front caused by the friction pressure drop corresponds to a deeper depth. Going on with the research about well dynamic behavior, mud flow rate is lowered from $280 \mathrm{gpm}$ to $100 \mathrm{gpm}$ and the corresponding front is $-328 \mathrm{psi}$. Finally, when the pumps are broken off the discontinuity is $1100 \mathrm{psi}$, meaning that oil well returns again to static conditions, $0 \mathrm{gpm}$. The minus sign (-) indicates that the front wave increases with depth and travels in opposite flow direction in the drillstring.

Figure 3 presents the full history of hydraulics simulation considering $t_{\text {Max }}=50 \mathrm{~s}$ and a real oil-well configuration. The well geometry is depicted on the right square using data from Table 1. The variations of mud flow rate are shown on the upper square; and in the main square the results of the 
transient hydraulic simulations are shown. It includes profiles of transient pressure (upper part) and transient flow rate (lower part). The drilling hydraulics is analyzed at well depths corresponding to surface $(0 \mathrm{ft}), 4921 \mathrm{ft}$ (didactic simulation), and bottom hole (11975 ft). Blue lines indicate dynamic flow conditions inside the drill string and red lines are for annular space. Initial $(t=0 \mathrm{~s})$ and left boundary conditions (flow rates) are displayed in the upper section. These surface data are usually observed and controlled at drilling floor. At the same time, the predicted hydraulics is validated against numerical data gotten from [5].
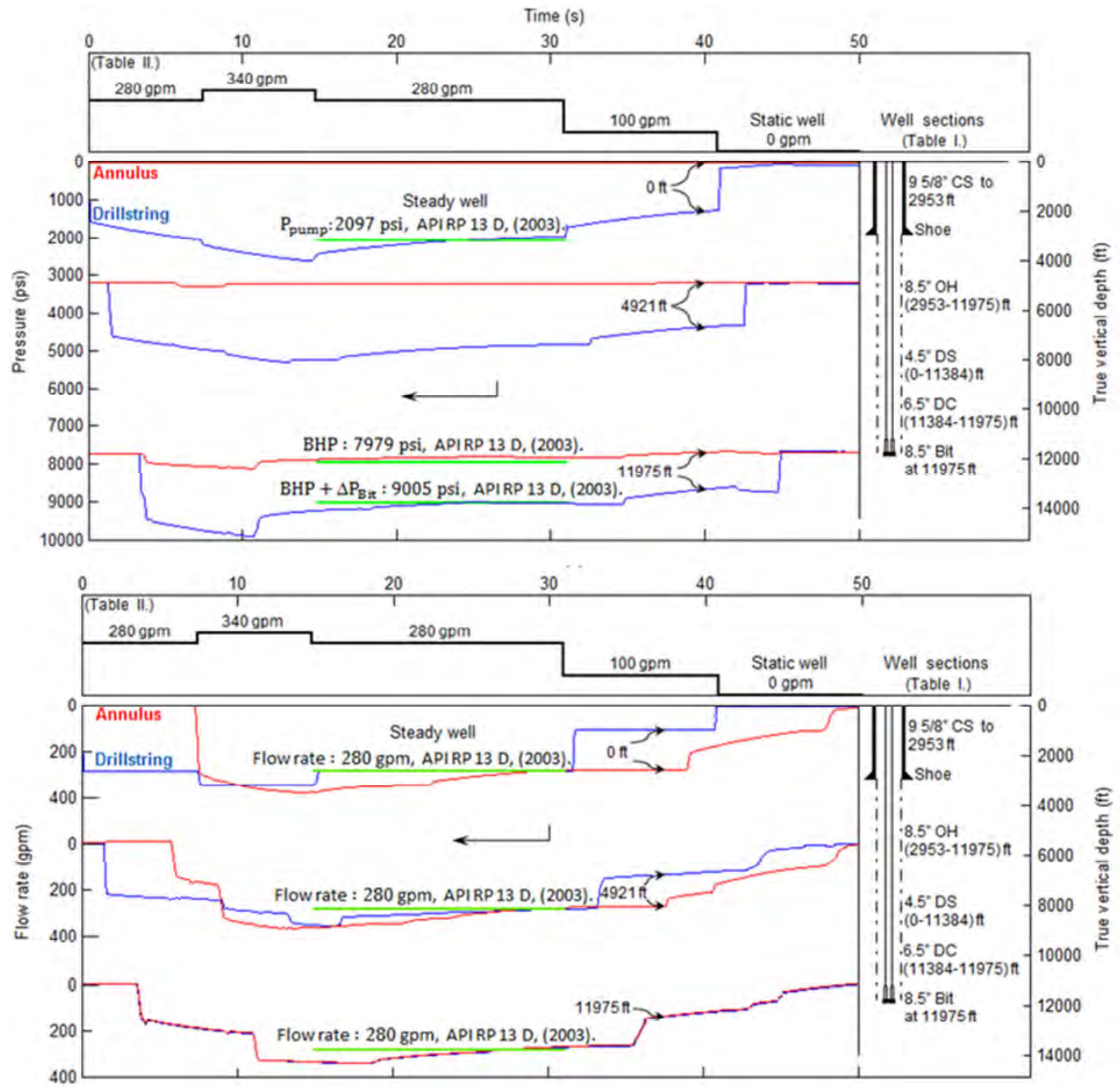

Figure 3. History of simulation including initial-boundary conditions, oil-well configuration, profiles of transient pressure and transient liquid flow rate. Blue and red lines denote the transient profiles of drillstring and annulus, respectively. Last casing CS, open hole OH, drillstring DS, drill collars DC, pumping pressure $P_{\text {pump }}$, bottom-hole pressure BHP, pressure drop in drill bit $\Delta P_{B i t}$.

For the case of transient pressures, the right boundary states that circulating mud is returned out of annulus at atmospheric condition. The "open-to-atmosphere" drilling methods use the gauge pressure $p$ as a reference pressure equal to $0 \mathrm{psi}$ at atmospheric condition. However the mathematical model is not restricted to this, a backpressure can be considered. Also, we take into account that some closure mathematical models require absolute pressure that is equivalent to gauge pressure plus atmospheric pressure
(14.67 psi). Based on this assumption, this research is focused on two important data which are dynamic bottomhole pressure BHP and pumping pressure $\mathrm{P}_{\text {pump. They are }}$ mainly results of transient pressure drop and changes of potential energy. At static well conditions, the hydrostatic head exerted by mud density of 12.43 ppg defines pressure profiles against depth. For instance, at $11975 \mathrm{ft}$, the initial value for BHP is 7735 psi. After $3.7 \mathrm{~s}$, it begins to increase when $280 \mathrm{gpm}$ flows in the total depth. At the same time, in 
drillstring pressure the pressure drop in drill bit $\Delta \mathrm{P}_{\mathrm{Bit}}$ is taken in account. This fact represents the separation between annulus and drillstring profiles. Oil-well dynamic condition is reached when the $280 \mathrm{gpm}$ reaches the surface end of annulus after $7.4 \mathrm{~s}$. At this time, mud flow rate is stepped up to $340 \mathrm{gpm}$ and the corresponding BHP and $\mathrm{P}_{\text {pump }}$ are 8071 psi and 2051 psi respectively. During the next two flow steps, 280 gpm and 100 gpm, BHP exhibits small oscillations about 7881 psi, 7821 psi, and 7678 psi. At $40 \mathrm{~s}$, rig pumps are turned off from 1283 psi to dead state. In consequence, injected flow rate is $0 \mathrm{gpm}$. Clearly, as a result of the inertial phenomenon of the pressure wave travelling, the well flows as similarly as to the starting of a well kick through the annulus. This dynamic well behavior can also be exaggerated when it is combined with an open-hole ballooning effect. Finally, at $50 \mathrm{~s}$, the oil well returns to the static state.

\section{Conclusions}

The numerical modeling of the wellbore drilling hydraulics was carried out applying the transient Godunov scheme considering variations of the injected flow rates. The developed theoretical model is able to describe the complete cycle of oil-well transient hydraulics; it is based on the pressure wave travelling inside of drill pipe and annulus from well static condition to transient, steady, and static conditions again. Initial and boundary conditions are well established with the oil-well geometry and dynamic operational conditions of the drilling hydraulics. The corresponding finite-volume method was encoded and solved utilizing the Riemann problem for the entire time-space domain. The spikes induced in the bottom-hole pressure as a result of adjustments or variations in the rig pump rate are discussed with an oil-well drilling described in [6]. Also, it was quantitatively demonstrated that pressure and liquid-flow rate profiles oscillate in the well sections. These facts suggest that the potential application of the Godunov scheme in automatic systems of managed pressure drilling.

\section{Acknowledgements}

Authors wish to state their appreciation to Instituto Mexicano del Petróleo for its permission to publish this article.

\section{Appendix}

A numerical application was reported considering flow in a pressurized pipe [14]. It consists of analyzing the dependence between the sound celerity and pressure for twophase flow in pipes. The physical domain is a circular pipe with $11 \mathrm{ft}^{2}$ and $1640 \mathrm{ft}$ of cross section and length, respectively. The working fluid has a density of $8.34 \mathrm{ppg}$ and sound celerity of $3281 \mathrm{ft} / \mathrm{s}$. The void fraction is assumed to be constant at $0.2 \%$. The transient phenomena start from the static fluid at pressure of $14.5 \mathrm{psi}$, next, the pressure at the left-hand boundary is lowered to 1.45 psi. It causes a rarefaction wave travelling to the right, when the wave reaches the right-hand boundary it is reflected and propagates to the left along the pipe. Herein, the evolution of the pressure profile has been replicated in order to extend properly this scheme for oil-well simulations.

The computation of data plotted in Figure 4 honors the numerical parameters and computation schemes described by [10], [14]. Logically, this strategy assures consistency, stability of our discrete solution model and to optimize the time budget for oil-well simulations.

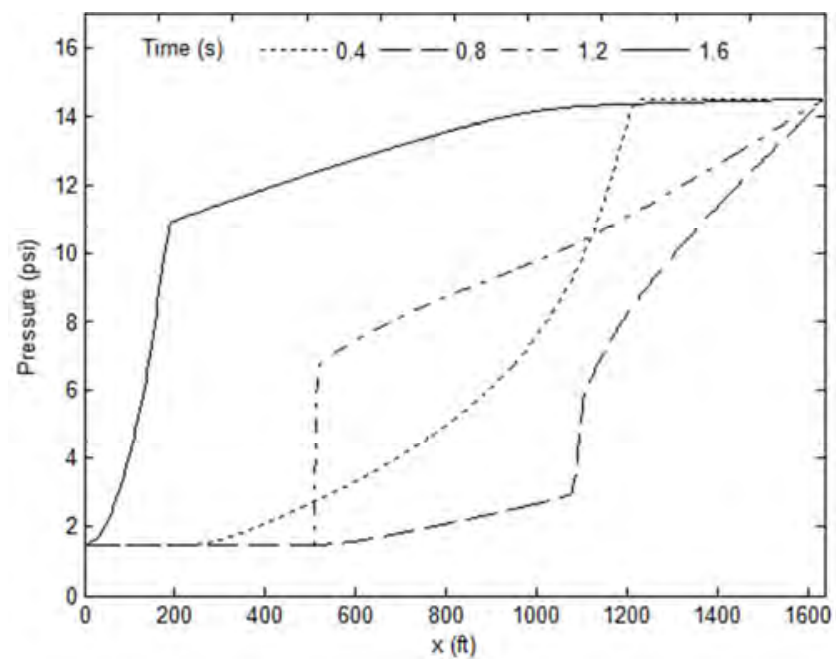

Figure 4. Numerical solution of two-phase flow in pipe [14].

\section{References}

[1] Guo, B, Hareland, G, Rajtar, J. Computer simulation predicts unfavorable mud rate and optimum air injection rate for aerated mud drilling, SPE drilling \& completion 1996: 61-66. DOI: $10.2118 / 26892-P A$.

[2] Bourdarias, CS, Gerbi, S. A finite volume scheme for a model coupling free surface and pressurized flows in pipes, Journal of Computational and Applied Mathematics, 2007; 209(1): 109-131. DOI: 10.1016/j.cam.2006.10.086.

[3] Kerger, F, Archambeau, P, Erpicum, S, Dewals, BJ, Pirotton, M. An exact Riemann solver and a Godunov scheme for simulating highly transient mixed flows, Journal of Computational and Applied Mathematics, 2011, 235 (8): 2030-2040. DOI: 10.1016/j.cam.2010.09.026.

[4] Flores-León, JO, Cázarez-Candia O, Nicolás-López R. Singleand two-phase flow models for concentric casing underbalanced drilling. In: Fluid Dynamics in Physics, Engineering and Environmental Applications, pp. 225-232, Springer-Verlag Berlin Heidelberg, Germany. ISBN: 978-3642-27722-1, 2013.

[5] Udegbunam, JE, Fjelde, KK, Evje, S, Nygaard, G. On the Advection-Upstream-Splitting-Method Hybrid Scheme: A Simple Transient-Flow Model for Managed-Pressure-Drilling and Underbalanced-Drilling Application, SPE Drilling \& Completion, SPE Paper No. 168960, 2015: 98-109. DOI: 10.2118/168960-PA.

[6] API RP 13D. Recommended practice on the rheology and hydraulics of oil-well drilling fluids, Fifth edition, Washington, DC, American Petroleum Institute, 2003. 
[7] Torkiowei V. and Zheng S. A new approach in pressure transient analysis: Using numerical density derivatives to improve diagnosis of flow regimes and estimation of reservoir properties for multiple phase flow, 2015, Journal of Petroleum Engineering, Article ID 214084. DOI: 10.1155/2015/214084.

[8] Naganawa S., Sato R., and Ishikawa M., Cuttings-transport simulation combined with large-scale-flow-lopp experimental results and logging-while-Drilling data for hole-cleaning evaluation in directional drilling, 2017, SPE Paper No. 171740, SPE Drilling \& Completion.

[9] Aragall R., Oppelt J. and Koppe M, Extending the scope of real-time drilling \& well control simulators, 2017, 13th Offshore Mediterranean Conference and Exhibition in Ravenna, Italy, March 29-31, SPE Paper No. OMC-2017-694.

[10] Guinot, V. Godunov-type schemes: An introduction for engineers, Chap. 2, 5. Elsevier Science B. V., Amsterdam, The Netherlands. ISBN: 9780444511553, 2003.
[11] Chaudhry, MH. Applied hydraulic transients, Third edition, Springer, New York, USA. ISBN: 978-1-4614-8537-7, 2014.

[12] SPE, The SI metric system of units and SPE metric standard, 1984, 2 dn Edition, Texas, USA.

[13] Benkhaldoun, F, Seaïd, M. A simple finite volume method for the shallow water equations, Journal of Computational and Applied Mathematics, 2010; 234(1): 58-72, DOI: 10.1016/j.cam.2009.12.005.

[14] Guinot, V. Numerical simulation of two-phase flow in pipes using Godunov method, International journal for numerical methods in engineering, 2001; 50(5): 1169-1189, DOI: 10.1002/1097-0207(20010220)50: $5<1169$.

[15] Nicolás-López, R, Valdiviezo-Mijangos OC, Valle-Molina C. New approach to calculate the mud density for wellbore stability using the asymptotic homogenization theory, Petroleum Science and Technology, 2012; 30(12): 1239-1249. DOI: $10.1080 / 10916466.2010 .503215$. 